\title{
Aspectos Clínicos Do Mieloma Múltiplo Cursando Com Insuficiência Renal: Relato De Caso Clínico
}

\author{
Silveira, G.V.; Jornada, F.M.; Tornatore, A.R.; Accorsi, B.F.; \\ Apresentador: Guilherme Vilarino da Silveira
}

\section{Resumo}

Introdução: O Mieloma Múltiplo (MM) é uma patologia caracterizada por uma proliferação maligna de plasmócitos e uma subsequente abundância de paraproteína monoclonal. A incidência anual nos EUA é de 4,3/100 000 homens brancos, 3/100 000 mulheres brancas, 9,6/100 000 homens negros e $6,7 / 100000$ mulheres negras. A mediana de idade de indivíduos com MM é 68 para homens e 70 para mulheres. Relato de caso: Paciente de 71 anos interna na enfermaria devido a quadro de múltiplas infecções urinárias, anemia, cansaço, astenia e insuficiência renal grave, com sintomas urêmicos e creatinina acima de $10 \mathrm{mg} /$ dl.Já estava em acompanhamento com a oncologia para pesquisa da anemia e lesões líticas em TC de tórax, tendo realizado biópsia de medula óssea. Paciente iniciou hemodiálise durante internação, porém não realizou biópsia renal devido atrofia renal em ultrassom feito na internação. Durante internação foi tratada para a infecção urinária, apresentando melhora. Foi realizado eletroforese de proteínas que demonstrou presença de pico monoclonal na região das gamaglobulinas. A biópsia de medula óssea evidenciou medula óssea hipercelular infiltrada por plasmócitos displásicos compatível com MM. Após diagnóstico paciente foi encaminhada para acompanhamento oncológico para realizar quimioterapia e continua fazendo diálise devido doença renal crônica possivelmente causada devido lesão renal pelas cadeias leves da imunoglobulina secretada pelos plasmócitos. Discussão e revisão de literatura: $\mathrm{O}$ crescimento descontrolado das células do mieloma tem muitas conseqüências, entre elas, destruição óssea, insuficiência da medula óssea, aumento do volume plasmático e da viscosidade, supressão da produção normal de imunoglobulina e insuficiência renal. No rim o mecanismo mais comum é injúria tubular devido a amiloidose ou envolvimento por plasmacitoma. Ainda, pode-se ter nefropatia hipercalcêmica, hiperuricemia devido a infiltração renal de plasmócitos resultando em mieloma e glomeruloesclerose. Insuficiência renal é encontrada em $25 \%$ dos pacientes com MM incluindo aí amiloidose de cadeias leves, nefrocalcinose devido a hipercalcemia e síndrome do rim com mieloma devido a múltiplas etiologias.

\section{Referência:}

Silveira, G.V.; Jornada, F.M.; Tornatore, A.R.; Accorsi, B.F.;. Aspectos Clínicos Do Mieloma Múltiplo Cursando Com Insuficiência Renal: Relato De Caso Clínico. In: II Congresso Brasileiro de Medicina Hospitalar - II CBMH [= Blucher Medical

Proceedings, vol.1, num.5] São Paulo: Editora Blucher, 2014. p.33

DOI 10.5151/medpro-II-cbmh-026 